\title{
Assessment of Patients' Satisfaction following Coverage of Gingival Recessions: Questionnaire- Based Case Series
}

\section{SUMMARY}

Background/Aim: One of the most important goals of periodontal plastic surgery constitutes the predictable root coverage. Despite the thorough documentation that several surgical approaches can be implemented for the successful treatment of gingival recession (GR), only limited papers reported data on the evaluation according to patient's opinion. Thus, the forthcoming study is aiming in the patient-based assessment of the outcome of root coverage procedures. Material and Methods: Sixteen subjects (eight male, eight female; mean age 43.75 years, range: 23-73 years), with twenty one GRs, constituted the sample of this study and the root coverage procedures were executed in the period from 2011 to 2019. A patient-based questionnaire was used to assess the level of subjects' concern on various aspects related to the GR, preand post-operatively. Patient's overall post-operative satisfaction was evaluated with a VAS. Results: After a period of at least 6 months of the surgical treatment, the majority of the subjects indicated that they were not concerned for all the examined criteria. The criteria with the highest improvement (reported as improvement by at least two levels of concern pre- and post-operatively) were the following: 1) fear to lose the involved teeth and 2) esthetics of the area of the recession defect. With regard to esthetics' criteria, the majority of the patients indicated post-operatively the examined criteria as not important. The esthetics' criteria yielding the highest improvement were: 1) position of the teeth and 2) the fact that the teeth showed longer. Mean patient's overall post-operative satisfaction was 82,3 (range: 0-100). Conclusions: The majority of the subjects were satisfied from the implemented root coverage procedures. Few studies on the international literature have evaluated patient satisfaction following therapy. Comprehensive, multi-center studies, comprised of a large sample and a using a standardized approach are needed in future research.

Key words: Gingival Recession, Patient Satisfaction, Patient Outcome, Root Coverage Procedures
Eleftherios Mitsopoulos, Panagiotis

Karakostas, Lazaros Tsalikis

Department of Preventive Dentistry,

Periodontology and Implant

Biology, Aristotle University of Thessaloniki,

Thessaloniki Greece
ORIGINAL PAPER (OP)

Balk J Dent Med, 2021;92-99

\section{Introduction}

One of the most important goals of periodontal plastic surgery is the predictable root coverage in order to cope with patient concerns related to root exposure $^{1}$. The displacement of the gingival margin apical to the cemento-enamel junction (CEJ) leads to the exposure of the root surface, which characterizes gingival recession $(\mathrm{GR})^{2}$. In such defects, functional and esthetic implications might be observed in terms of root hypersensitivity, root caries, abrasion or esthetic complaints $^{3}$. Either periodontal disease or mechanical 
factors such as wrong way of toothbrushing might lead to the development of $\mathrm{GR}^{4}$. Esthetic concern, root hypersensitivity, abrasion or root caries, improved prognosis of dental restorations, prevention or management of periodontal disease in areas where hygiene is difficult to be maintained constitute the indications for the coverage of an exposed root surface ${ }^{5,6}$. Recent studies have indicated that esthetic concern has become the principal reason of performing a root coverage procedure $^{7,8}$.

There is thorough documentation that various surgical approaches can be used for the successful treatment of $\mathrm{GR}^{9,10}$, on condition that there is no loss of height on the interdental soft and hard tissues ${ }^{11}$. Effective elimination of the GR and stability of the obtained outcome constitute the two significant factors that characterize such surgical procedures as successful. The parameters that define an "ideal" root coverage procedure are the following: a) complete root coverage (CRC) of the GR defect, b) good appearance related to the neighboring gingival tissues and c) minimal probing depth ${ }^{11-13}$.

The subepithelial connective tissue graft (SCTG) constitutes the most predictable surgical approach in order to achieve $\mathrm{CRC}$ on an isolated type of $\mathrm{GR}^{12,14}$ However, there is possibility of graft exposure and thus, insufficient color match with the adjacent tissues and excessive soft tissue thickness can be observed ${ }^{15}$. Recent studies on isolated type of GRs reported that the combination of xenogenic collagen matrix (CMX) and coronally advanced flap (CAF) led to good clinical results, compared favorably with the outcomes obtained after the performance of a surgical procedure using $\mathrm{SCTG}^{16}$. Furthermore, this combination, when compared to CAFs alone, provided better results on soft tissue thickness and on subject-evaluated outcomes ${ }^{17}$. The envelope-type of $\mathrm{CAF}^{18}$ constitutes a safe and predictable procedure for the treatment $^{19}$ of multiple recession-type defects and there are more recent surgical approaches comprising of tunnel techniques that can be implemented to manage these patients $^{20}$.

Numerous studies in the literature refer to the treatment of GR, albeit just few papers report the esthetic evaluation from a patient's view ${ }^{21}$. Recently, European Federation of Periodontology underlined the fact that in order to have better alignment between professional endpoints and patient-reported outcomes, patients' perceptions and requests should be considered on future research ${ }^{22}$. Previous studies have used a variety of objective parameters to assess the efficacy of different surgical modalities such as $\mathrm{CRC}$, recession reduction or keratinized tissue increase. However, in the majority of those studies, patient concerns (ex. esthetics, root sensitivity), and therefore the true indications for treatment, were ignored. The definition of patientoriented outcomes is any report of someone's health condition coming directly from him/her. There is no interpretation of the reported data by any professional ${ }^{23}$. They are subjective and comprise of the measurement of patient opinions to difficult-to-quantify parameters, such as anxiety, pain and satisfaction ${ }^{21}$. The percentage of coverage of the root exposure constitutes an objective and quantitative measurement, and $\mathrm{CRC}$ characterizes GR defects that have successfully been treated ${ }^{24}$. Nevertheless, the most coronal $\mathrm{mm}(\mathrm{s})$ of the exposed root surface may be the only visible part on patient's smile; thus, should a shallow recession persist after the root coverage procedure, this will be considered an esthetic failure $^{25}$. In addition, despite the fact that CRC might be obtained after treatment of GR, it is possible that a scar and/ or poor color blending with the neighboring tissues may occur leading to impaired esthetics. Consequently, the outcome of GR treatment should not be defined solely by $\mathrm{CRC}^{7}$.

However, it has not yet been established a relationship between a periodontist's assessment after the performance of a root coverage procedure, who is an expertise, and the outcomes evaluated by patients, who lack of a background knowledge of such procedures. Therefore a discrepancy might be observed between patient's and clinician's satisfaction ${ }^{26}$.

Therefore, the forthcoming study is focusing on patient's evaluation of the outcome of root coverage procedures that were implemented for the treatment of GR defects on patients who referred to Department of Periodontology, School of Dentistry, Aristotle University of Thessaloniki for the correction of their problem. A thorough analysis was performed using patient-based questionnaires $^{27}$ and a $100 \mathrm{~mm}$ horizontal visual analog scale (VAS) was used for the assessment of patient's overall satisfaction post-operatively.

\section{Material and Methods}

\section{Anamnestic data}

Sixteen patients with single or multiple adjacent GRs were recruited for analysis. All the recessions fell into the class I according to the definition proposed by Cairo $^{28}$. According to Cairo classification, class I include GR defects without loss of interproximal attachment. A total of 21 recession defects were selected and the surgical procedures for their correction were performed in the period from 2011 to 2019 in the Department of Periodontology, School of Dentistry, Aristotle University of Thessaloniki. Emphasis was given in this study to the evaluation of patient-reported outcomes.

\section{Inclusion and exclusion criteria}

The study inclusion criteria were the following:

- $\quad$ Age $>18$ years

- Periodontally and systematically healthy 
- Cairo I recession defects Study exclusion criteria:

- smoking

- contraindications for periodontal surgery

- medications known to interfere with periodontal tissue health or healing.

\section{Study protocol}

Information about the aim of the study were given to all the participants and their participation was voluntary. The protocol of the study was approved by the Department of Preventive Dentistry, Periodontology and Implant Biology, School of Dentistry, Aristotle University of Thessaloniki.

\section{Initial therapy}

All the subjects initially completed a plaque-control program comprised of:

- oral hygiene instructions (including instructions for nontraumatic brushing technique with a soft toothbrush),

- scaling and root planing.

\section{Surgical procedures}

All the surgical procedures for the coverage of GR were executed by post-graduate students on the postgraduate clinic of Periodontology of the Department of Preventive Dentistry, Periodontology and Implant Biology of the School of Dentistry of Aristotle University of Thessaloniki, Greece. The treatment of recession included 7 different surgical techniques: 1) coronally advanced flap (CAF), 2) laterally rotated flap (LRF), 3) epithelialized connective tissue graft (known as a free gingival graft), 4) subepithelial connective tissue graft (SCTG) with a coronally advanced flap (CAF) [SCTG+CAF], 5) subepithelial connective tissue graft (SCTG) with double papilla flap (DPF) [SCTG+DPF], 6) Enamel matrix derivatives (EMD) with a coronally advanced flap (CAF) [EMD+CAF] and 7) Enamel matrix derivatives (EMD) with Minimal Invasive Surgical Technique (MIST) [EMD+MIST].

\section{Questionnaires}

Patients evaluated their esthetics perception at two different stages: the first was before the execution of the root coverage procedure (baseline) and the second was at least 6 months after the performance of the surgical treatment. A health-related quality-of-life tool, specified on root coverage procedures, with a 5-point Likert scale was used for assessing the level of concern of the following patient-centered criteria: a) esthetics, b) sensitivity to cold, c) sensitivity to brushing, d) root/ tooth wear, e) development of cavity and f) fear to lose the involved teeth ${ }^{27}$. A $100-\mathrm{mm}$ horizontal VAS was used in order to record patients' overall satisfaction postoperatively (left endpoint indicating very bad and right endpoint excellent). The questionnaire was administered by one of the investigators without the presence of the post-graduate student who had executed the root coverage procedure in order to keep anonymous answers and have an unbiased result.

\section{Results}

Sixteen patients ( 8 males and 8 females), with twenty one buccal GRs constituted the sample of the survey. The mean age of the sixteen patients was 43.75 years (range: 23-73 years). Population statistics are presented in Table 1.

Table 1. Population statistics

\begin{tabular}{lc}
\hline $\begin{array}{l}\text { Examined parameters of the } \\
\text { included population }\end{array}$ & $\begin{array}{c}\text { Number of patients (\% on } \\
\text { the whole of the included } \\
\text { population) }\end{array}$ \\
\hline Gender & \\
Male & $8(50)$ \\
Female & $8(50)$ \\
Education & \\
No education & $0(0)$ \\
Elementary & $0(0)$ \\
Secondary & $6(37.50)$ \\
University education & $10(62.50)$ \\
Occupation & \\
Employed & $11(68.75)$ \\
Unemployed & $3(18.75)$ \\
Retired & $2(12.50)$ \\
Residence & \\
Urban & $13(81.25)$ \\
Rural & $3(18.75)$ \\
\hline
\end{tabular}

Fifty teeth with GRs were treated and the teeth of interest were free of plaque and gingival inflammation before the root coverage procedure and throughout the study. The mean number of GRs treated per subject was 2.38 (range: 1-9). Fourteen recessions were located in the upper arch, while the rest were located in the lower jaw. Table 2. briefly presents the 21 treated defects, and patient's post-operative satisfaction with VAS. 
Table 2. Population and defects characteristics

\begin{tabular}{|c|c|c|c|c|c|c|}
\hline Case & Age & Gender & $\begin{array}{c}\text { Cairo classification } \\
\text { of GR }\end{array}$ & Location of the GR & Surgical procedure & $\begin{array}{l}\text { Patient assessment of } \\
\text { the procedure result } \\
\text { (VAS mm) }\end{array}$ \\
\hline 1 & 29 & $\mathrm{~F}$ & I & $\begin{array}{l}\# 11 \text { and } \\
\# 22-23\end{array}$ & $\begin{array}{c}(\# 11) \text { CAF } \\
\text { and(\#22-23) SCTG+CAF }\end{array}$ & 100 \\
\hline 2 & 24 & M & I & $\# 31$ & Free gingival graft & 90 \\
\hline 3 & 47 & M & I & $\# 12-14$ & $\mathrm{SCTG}+\mathrm{CAF}$ & 100 \\
\hline 4 & 44 & M & I & $\# 12-14$ & EMD+MIST & 99 \\
\hline 5 & 44 & $\mathrm{~F}$ & I & $\# 14$ & Free gingival graft & 0 \\
\hline 6 & 51 & $\mathrm{~F}$ & I & \#32-42 & Free gingival graft & 100 \\
\hline 7 & 36 & $\mathrm{~F}$ & I & $\# 23$ & $\mathrm{SCTG}+\mathrm{CAF}$ & 98 \\
\hline 8 & 36 & $\mathrm{~F}$ & I & $\# 13$ & $\mathrm{EMD}+\mathrm{CAF}$ & 50 \\
\hline 9 & 28 & $\mathrm{~F}$ & I & $\# 16$ & LPF & 60 \\
\hline 10 & 28 & $\mathrm{~F}$ & I & $\# 13-14$ & $\mathrm{EMD}+\mathrm{CAF}$ & 60 \\
\hline 11 & 28 & $\mathrm{~F}$ & I & $\# 23-25$ & $\mathrm{SCTG}+\mathrm{CAF}$ & 90 \\
\hline 12 & 28 & $\mathrm{~F}$ & I & \#42 & Free gingival graft & 40 \\
\hline 13 & 57 & $\mathrm{~F}$ & I & $\# 13-26$ & CAF & 100 \\
\hline 14 & 73 & M & I & \#33 & EMD+MIST & 100 \\
\hline 15 & 51 & M & I & \#32-42 & Free gingival graft & 100 \\
\hline 16 & 32 & M & I & $\# 31$ & $\mathrm{SCTG}+\mathrm{DPF}$ & 98 \\
\hline 17 & 67 & M & I & $\# 13$ & LPF & 100 \\
\hline 18 & 67 & M & I & \#12 & CAF & 100 \\
\hline 19 & 36 & $\mathrm{~F}$ & I & $\# 31-42$ & $\mathrm{SCTG}+\mathrm{CAF}$ & 100 \\
\hline 20 & 30 & M & I & $\# 13-14$ & $\mathrm{SCTG}+\mathrm{CAF}$ & 94 \\
\hline 21 & 57 & $\mathrm{~F}$ & I & \#23-25 & SCTG+CAF & 49 \\
\hline
\end{tabular}

Patient overall satisfaction post-operatively with VAS ( 0 indicating very bad, 50 indicating average, 100 indicating excellent) was 82,3 (range: $0-100$ ). On nine cases the patients were completely satisfied by the root coverage procedure, as it is demonstrated by the excellent VAS score (100), while on six other cases the patients evaluated the procedure as almost excellent (VAS score: 90-99). Five cases were assessed from the patients just above or below average (VAS score: 40-60) and just in one case the patient was not satisfied at all from the surgery, as it can be indicated by the VAS score (0).

Pre- and post- surgery recordings for the level of concern of the examined aspects are demonstrated in Tables 3 and 5, while Tables 4 and 6 demonstrate patient's perceptions with regard to esthetics pre- and postoperatively.

Table 3. Patients'perceptions pre-operatively

\begin{tabular}{|c|c|c|c|c|c|c|}
\hline & & $\begin{array}{c}\text { No } \\
\text { concern }\end{array}$ & $\begin{array}{l}\text { A little } \\
\text { concern }\end{array}$ & $\begin{array}{c}\text { Some } \\
\text { Concern }\end{array}$ & $\begin{array}{c}\text { Quite a bit of } \\
\text { concern }\end{array}$ & $\begin{array}{l}\text { Lots of } \\
\text { concern }\end{array}$ \\
\hline A & Esthetics & $4(19 \%)$ & $4(19 \%)$ & $3(14.3 \%)$ & $4(19 \%)$ & $6(28.6 \%)$ \\
\hline $\mathrm{B}$ & Sensitivity to cold & $4(19 \%)$ & $2(9.5 \%)$ & $8(38.1 \%)$ & $4(19 \%)$ & $3(14.3 \%)$ \\
\hline $\mathrm{C}$ & Sensitivity to brushing & $10(47.6 \%)$ & $2(9.5 \%)$ & $3(14.3 \%)$ & $6(28.6 \%)$ & $0(0 \%)$ \\
\hline $\mathrm{D}$ & Wear of root surface & $5(23.8 \%)$ & $4(19 \%)$ & $4(19 \%)$ & $5(23.8 \%)$ & $3(14.3 \%)$ \\
\hline $\mathrm{E}$ & Development of cavity & $7(33.3 \%)$ & $4(19 \%)$ & $3(14.3 \%)$ & $4(19 \%)$ & $3(14.3 \%)$ \\
\hline $\mathrm{F}$ & Fear to lose the tooth & $3(14.3 \%)$ & $2(9.5 \%)$ & $6(28.6 \%)$ & $3(14.3 \%)$ & $7(33.3 \%)$ \\
\hline
\end{tabular}


Table 4. Patients' perceptions with regard to esthetics, pre-operatively

\begin{tabular}{|c|c|c|c|c|c|c|}
\hline & & $\begin{array}{c}\text { Not } \\
\text { important }\end{array}$ & $\begin{array}{c}\text { Little } \\
\text { important }\end{array}$ & $\begin{array}{l}\text { Somehow } \\
\text { important }\end{array}$ & Quite important & Very importan \\
\hline $\mathrm{A}$ & Position of the teeth & $4(19 \%)$ & $1(4.8 \%)$ & $2(9.5 \%)$ & $7(33.3 \%)$ & $7(33.3 \%)$ \\
\hline A & Longer teeth & $5(23.8 \%)$ & $5(23.8 \%)$ & $1(4.8 \%)$ & $7(33.3 \%)$ & $3(14.3 \%)$ \\
\hline B & Uneven gingival margin & $4(19 \%)$ & $5(23.8 \%)$ & $3(14.3 \%)$ & $5(23.8 \%)$ & $4(19 \%)$ \\
\hline $\mathrm{C}$ & Tooth color & $9(42.9 \%)$ & $1(4,8 \%)$ & $2(9.5 \%)$ & $4(19 \%)$ & $5(23.8 \%)$ \\
\hline $\mathrm{D}$ & Gum color & $9(42.9 \%)$ & $2(9.5 \%)$ & $2(9.5 \%)$ & $4(19 \%)$ & $4(19 \%)$ \\
\hline
\end{tabular}

Table 5. Patients' perceptions post-operatively

\begin{tabular}{llccccc}
\hline & $\begin{array}{c}\text { No } \\
\text { concern }\end{array}$ & $\begin{array}{c}\text { A little } \\
\text { concern }\end{array}$ & $\begin{array}{c}\text { Some } \\
\text { concern }\end{array}$ & $\begin{array}{c}\text { Quite a bit of } \\
\text { concern }\end{array}$ & $\begin{array}{c}\text { Lots of } \\
\text { concern }\end{array}$ \\
\hline A & Esthetics & $12(57.1 \%)$ & $5(23.8 \%)$ & $3(14.3 \%)$ & $0(0 \%)$ & $1(4.8 \%)$ \\
B & Sensitivity to cold & $11(52.4 \%)$ & $7(33.3 \%)$ & $1(4.8 \%)$ & $1(4.8 \%)$ & $1(4.8 \%)$ \\
C & Sensitivity to brushing & $17(81 \%)$ & $1(4.8 \%)$ & $2(9.5 \%)$ & $0(0 \%)$ & $1(4.8 \%)$ \\
D & Wear of root surface & $14(66.7 \%)$ & $6(28.6 \%)$ & $0(0 \%)$ & $0(0 \%)$ & $1(4.8 \%)$ \\
E & Development of cavity & $18(85.7 \%)$ & $0(0 \%)$ & $1(4.8 \%)$ & $1(4.8 \%)$ & $1(4.8 \%)$ \\
F & Fear to lose the tooth & $18(85.7 \%)$ & $1(4.8 \%)$ & $1(4.8 \%)$ & $0(0 \%)$ & $1(4.8 \%)$ \\
\hline
\end{tabular}

Table 6. Patients' perceptions with regard to esthetics, post-operatively

\begin{tabular}{|c|c|c|c|c|c|c|}
\hline & & $\begin{array}{c}\text { Not } \\
\text { Important }\end{array}$ & $\begin{array}{c}\text { Little } \\
\text { important }\end{array}$ & $\begin{array}{l}\text { Somehow } \\
\text { important }\end{array}$ & Quite important & Very important \\
\hline A & Position of the teeth & $12(57.1 \%)$ & $4(19 \%)$ & $2(9.5 \%)$ & $0(0 \%)$ & $3(14.3 \%)$ \\
\hline A & Longer teeth & $14(66.7 \%)$ & $6(28.6 \%)$ & $0(0 \%)$ & $0(0 \%)$ & $1(4.8 \%)$ \\
\hline $\mathrm{B}$ & Uneven gingival margin & $14(66.7 \%)$ & $4(19 \%)$ & $2(9.5 \%)$ & $0(0 \%)$ & $1(4.8 \%)$ \\
\hline $\mathrm{C}$ & Tooth color & $15(71.4 \%)$ & $2(9.5 \%)$ & $2(9.5 \%)$ & $1(4.8 \%)$ & $1(4.8 \%)$ \\
\hline $\mathrm{D}$ & Gum color & $16(76.2 \%)$ & $3(14.3 \%)$ & $0(0 \%)$ & $1(4.8 \%)$ & $1(4.8 \%)$ \\
\hline
\end{tabular}

Assessment according to esthetics demonstrates that the level of concern of the patients was ranging from no concern to lots of concern pre-operatively. For all the treatments, on 3 cases there was no change in the concern level about esthetics from baseline to re-examination, while improvement reported, as measured by at least one gain in concern level, on 8 cases. On the rest 10 cases, improvement was found by at least two concern levels.

Regarding sensitivity to cold, on 4 cases, the subjects on the re-examination, were as concerned as they were on baseline about this aspect. On 8 cases it was reported improvement by one concern level and advance by at least two concern levels, was found on 8 other cases. In one case, the subject pre-operatively was a little concerned about sensitivity to cold, but on re-examination she had lots of concern on this aspect.
As for sensitivity to brushing, in 10 cases there was no change in patient responses pre- and post-operatively. 3 cases presented improvement by one concern level and 7 cases by at least two concern levels. In one case, the subject pre-surgical was a little concerned about sensitivity to brushing, but on re-examination she had lots of concern on this aspect.

Evaluation according to wear of the root surface demonstrated that there was no change on the concern level of 6 cases. Improvement by one concern level was found on 5 cases and 9 cases demonstrated improvement by at least two levels. In one case, the patient was quite a bit concerned pre-operatively, but she had lots of concern on re-examination.

As for the fear to lose the involved teeth, on 4 cases, there was no change, on the concern level from baseline to 
re-examination. On 2 cases it was reported improvement by one level, while improvement by at least two levels was found on the rest 12 cases.

Assessment according the development of cavity shows that 9 cases presented no change on the concern level from baseline to re-examination. 5 cases demonstrated improvement by one level and the rest 7 cases by at least two concern levels.

With regard to aesthetics, and especially about the position of the tooth, on the most cases (11 cases) there was an improvement by at least two levels pre- and postoperatively, on 2 cases improvement by one level and on 7 cases no change. In one case there was the deterioration by one level.

As for the fact that the tooth showed longer, on 10 cases it was reported improvement by at least two concern levels from baseline to re-examination. 2 cases demonstrated improvement by one level, while the rest 9 cases showed no response change.

The responses to the uneven gingival margin were ranging from not important to very important presurgigal. Improvement by at least two levels was reported on 9 cases, while improvement by one level was found on 5 cases. On 7 cases there was not any change in the response to this aspect pre- and post-surgical.

Regarding the tooth color and the gum color, on the majority of the cases (12 cases) there was no change on the concern level, pre- and post-operatively for both aspects. In one case, it was reported improvement by one level and 8 cases demonstrated improvement by at least two levels.

\section{Discussion}

The aim of the present study was to evaluate patients' concerns before the root coverage procedure (at baseline) about esthetics, sensitivity to cold, sensitivity to brushing, root/tooth wear, development of cavity and fear to lose the involved teeth, and the assessment of the same criteria post-operatively at least 6 months after the surgery. The study was conducted on a carefully selected population of Cairo I single or multiple buccal GRs, treated by post-graduate students of the Department of Preventive Dentistry, Periodontology and Implant Biology of the School of Dentistry of Aristotle University of Thessaloniki, Greece with well-standardized surgical procedures. Patients of short- and long-term followup were included in the study, while all of the patient reexaminations were executed in the period from April 2019 to June 2019.

Pre-operatively, most of the subjects were concerned, on different levels, about the examined criteria related to the GRs. The majority of the patients (above $50 \%$ ) were satisfied from the root coverage procedures as it can be demonstrated from the VAS assessment and the changes on the patients' responses on the questionnaires from baseline to reexamination. Some subjects still had-a little, some or quite a bit- concern about some aspects, post-operatively. But, only one subject was not satisfied at all (VAS score: 0) from the surgery and reported lots of concern regarding all the examined aspects postoperatively.

Numerous publications have thoroughly assessed the effectiveness of various root coverage procedures. Nevertheless, given that there are insufficient data in the periodontal literature about esthetic condition change related to patient's view and preference for a specific surgical procedure ${ }^{16}$, there is necessity for further investigation of such procedures.

A study ${ }^{29}$, which compared the perception of dentists and lay people to altered dental esthetics, led to the following conclusions: patient-oriented outcomes were found to be less stringent than professionally evaluated outcomes and patients did not seem to be as critical as clinicians. Consequently, the "ideal", as judged by a clinician, might not always be necessary. The goal in private practice is enhanced patient-reported outcomes ${ }^{16}$. Generally, patients tend to evaluate the esthetic outcomes more favorably than the professionals ${ }^{8}$ and the reason for this discrepancy is not yet clarified. For instance, insignificant differences in color match or in tissue thickness are more likely to concern the patients than an incomplete coverage of the root surface. Patient's esthetic perception is subjective and certainly constitutes an important reason for this difference and differences can be reported not only between patient and clinician but also between patients ${ }^{21}$. Additionally, another factor, whose influence to esthetic satisfaction is equally important, is someone's cultural background, a factor difficult to assess and comprising of numerous subjective variables ${ }^{26}$.

Furthermore, patient's perception of GR defects is usually underrated in professional practice ${ }^{30}$ and there is no information, available in the literature, showing whether patient's approach and requests affect the type of the treatment that will be performed (surgical or nonsurgical). Commonly, the clinician is the one who decide the implemented treatment and the main factors leading to his/her decision are the following: a) his/her knowledge, b) the level of clinical experience and c) the financial benefit ${ }^{31,32}$.

Even though the most reliable data about treatment outcomes stem from randomized clinical trials (RCTs), patient's opinion should be considered as a legitimate method of assessing perioplastic esthetic procedures ${ }^{33}$. There are not many studies in the literature that have tried to record patient satisfaction after a root coverage procedure. Moreover, there is not a standardized approach in order to accomplish that. A VAS or a 5-point scale were used on those studies for determining patient's satisfaction pre- or post-operatively. After an in-depth review of the 
periodontal literature, it was concluded that the majority of the existing studies are RCTs or comparative studies between two specific root coverage procedures. Therefore, they could not be used for comparison with this study, which constitutes a case-series study, with a significant heterogeneity of the performed surgical procedures.

A meta-analysis review on root-coverage procedures, conducted by Cairo et al. ${ }^{34}$, included a total of 16 RCTs. It was concluded that the periodontal plastic surgery techniques with the highest probability of obtaining a satisfactory esthetic result (as judged by the patient), were those applying SCTG underneath a CAF with or without EMD. This finding suggests that perioplastic techniques, where SCTG is included, provide higher patient satisfaction.

The present study shares a limitation as regards to its small sample and heterogeneity of the implemented surgical procedures on the presented cases. Future recommendation constitutes the need to focus research on patient's opinion and requests. Comprehensive studies, including those with a large sample and using a prospective and standardized approach would be desirable in order to assess patient's perception outcomes on root coverage procedures.

\section{Conclusions}

The literature presents limited documentation on the evaluation of the GR treatment from a patient's view. Our study focused on patient's perceptions of their GRs preoperatively and patient's perception outcomes of the GR treatment post-operatively.

With regard to the examined criteria, it can be reported that most of the patients were concerned, on different levels, about their GRs pre-surgical. Within the strong limitations of this study, it could be concluded that the majority of the subjects seemed to be satisfied from the outcome of the implemented root coverage procedure, as it can be demonstrated from the VAS-assessments and the changes in the responses on the patient-based questionnaires pre- and post-surgical.

However, comprehensive studies, comprised of a large sample and using a prospective and standardized approach, would be desirable in future research, in the way to evaluate patient's perception outcomes on root coverage procedures.

\section{References}

1. Harris RJ. Root coverage with connective tissue grafts: An evaluation of short- and long-term results. J Periodontol, 2002;73:1054-1059.
2. Glossary of Periodontal Terms- American Academy of Periodontology. J Periodontol, 2001;4:177-179.

3. Trombelli L. Periodontal regeneration in gingival recession defects. Periodontol 2000, 1999;19:138-150.

4. Loe H, Anerud A, Boysen H. The natural history of periodontal disease in man: Prevalence, severity, and extent of gingival recession. J Periodontol, 1992;63:489-495.

5. Bouchard P, Malet J, Borghetti A. Decision-making in aesthetics: Root coverage revisited. Periodontol 2000, 2001;27:97-120.

6. Harris RJ. The connective tissue and partial thickness double pedicle graft: A predictable method of obtaining root coverage. J Periodontol, 1992;63:477-486.

7. Kerner S, Sarfati A, Katsahian S, Jaumet V, Micheau C, Mora F, et al. Qualitative cosmetic evaluation after rootcoverage procedures. J Periodontol, 2009;80:41-47.

8. Kim SM, Choi YH, Kim YG, Park JW, Lee JM, Suh JY. Analysis of the esthetic outcome after root coverage procedures using a comprehensive approach. J Esthet Restor Dent, 2014;26:107-118.

9. Wennstrom JL. Proceedings of the 1st European Workshop on Periodontology. Mucogingival surgery. In: Lang NP, Karring T, eds. Berlin: Quintessence Publishing; 1994:193209.

10. Wennstrom JL. Proceedings of the 1996 World Workshop in Periodontics. Ann Periodontol, 1996;1:667-701.

11. Miller PD. A classification of marginal tissue recession. Int $\mathrm{J}$ Periodontics Restorative Dent, 1985;5:8-13.

12. Roccuzzo M, Bunino M, Needleman I, Sanz M. Periodontal plastic surgery for treatment of localized gingival recessions: a systematic review. J Clin Periodontol, 2002;29:178-194

13. Clauser C, Nieri M, Franceschi D, Pagliaro U, Pini-Prato G. Evidence-based mucogingival therapy. Part 2: ordinary and individual patient data meta-analyses of surgical treatment of recession using complete root coverage as the outcome variable. J Periodontol, 2003;74:741-756.

14. Cairo F, Pagliaro U, Nieri M. Treatment of gingival recession with coronally advanced flap procedures. A systematic review. J Clin Periodontol, 2008; 35:136-162.

15. Zucchelli G, Amore C, Sforza NM, Montebugnoli L, De Sanctis M. Bilaminar techniques for the treatment of recession type defects. A comparative clinical study. J Clin Periodontol, 2003;30:862-870.

16. McGuire MK, Scheyer ET. Xenogeneic collagen matrix with coronally advanced flap compared to connective tissue with coronally advanced flap for the treatment of dehiscence- type recession defects. J Periodontol, 2010;81:1108-1117.

17. Stefanini M, Jepsen K, De Sanctis M, Baldini N, Greven B, Heinz B, et al. Patient- reported outcomes and aesthetic evaluation of root coverage procedures: A 12 months follow- up of a randomized controlled clinical trial. J Clin Periodontol, 2016;43:1132-1141.

18. Zucchelli G, De Sanctis M. Treatment of multiple recession-type defects in patients with esthetic demands. $\mathrm{J}$ Periodontol, 2000;71:1506-1514.

19. Zucchelli G, De Sanctis M. Long-term outcome following treatment of multiple Miller class I and II recession defects in esthetic areas of the mouth. J Periodontol, 2005;76:22862292. 
20. Aroca S, Molnar B, Windisch P, Gera I, Salvi GE, Nikolidakis D, et al. Treatment of multiple adjacent Miller class I and II gingival recessions with a Modified Coronally Advanced Tunnel (MCAT) technique and a collagen matrix or palatal connective tissue graft: A randomized, controlled clinical trial. J Clin Periodontol, 2013;40:713-720.

21. Mounssif I, Stefanini M, Mazzotti C, Marzadori M, Sangiorgi M, Zucchelli G. Esthetic evaluation and patientcentered outcomes in root-coverage procedures. Periodontol 2000, 2018;1:19-53.

22. Tonetti MS, Jepsen S. Clinical efficacy of periodontal plastic surgery procedures: consensus report of Group 2 of the 10th European Workshop on Periodontology. J Clin Periodontol, 2014;41:36-43.

23. US Department of Health and Human Services FDA, Center for Drug Evaluation and Research, Center for Biologics Evaluation and Research, Center for Devices and Radiological Health. Guidance for Industry. Patient-reported outcome measures: Use in medical product development to support labeling claims. Silver Spring, MD, 2009.

24. Rotundo R, Nieri M, Mori M, Clauser C, Prato GP Aesthetic perception after root coverage procedure. J Clin Periodontol, 2008;35:705-712.

25. Zucchelli G, Mele M, Mazzotti C, Marzadori M, Montebugnoli L,de Sanctis M. Coronally advanced flap with and without vertical releasing incisions for the treatment of multiple gingival recessions: a comparative controlled randomized clinical trial. J Periodontol, 2009;80:1083-1094.

26. Sacchini V, Luini A, Tana S, Lozza L, Galimberti V, Merson $\mathrm{M}$, et al. Quantitative and qualitative cosmetic evaluation after conservative treatment for breast cancer. Eur J Cancer, 1991;27:1395-1400.

27. Tonetti MS, Cortellini P, Pellegrini G, Nieri M, Bonaccini $\mathrm{D}$, Allegri $\mathrm{M}$, et al. Xenogenic collagen matrix or autologous connective tissue graft as adjunct to coronally advanced flaps for coverage of multiple adjacent gingival recession: Randomized trial assessing non-inferiority in root coverage and superiority in oral health-related quality of life. J Clin Periodontol, 2018;45:78-88.

28. Cairo F, Nieri M, Cincinelli S, Mervelt J, Pagliaro U. The interproximal clinical attachment level to classify gingival recessions and predict root coverage outcomes: an explorative and reliability study. J Clin Periodontol, 2011;38:661-666.
29. Kokich VO Jr, Kiyak HA, Shapiro PA. Comparing the perception of dentists and lay people to altered dental esthetics. J Esthet Dent, 1999;11:311-324.

30. Nieri M, Pini Prato GP, Giani M, Magnani N, Pagliaro U, Rotundo R. Patient perceptions of buccal gingival recessions and requests for treatment. J Clin Periodontol, 2013;40:707712.

31. Cortellini P, Pini Prato G. Coronally advanced flap and combination therapy for root coverage. Clinical strategies based on scientific evidence and clinical experience. Periodontol 2000, 2012;59:158-184.

32. Zucchelli G, Mounssif I. Periodontal plastic surgery. Periodontol 2000, 2015;68:333-368.

33. Mahajan A, Dixit J, Verma UP. A patient-centered clinical evaluation of acellular dermal matrix graft in the treatment of gingival recession defects. J Periodontol, 2007;78:23482355.

34. Cairo F, Pagliaro U, Buti J, Baccini M, Graziani F, Tonelli P, et al. Root coverage procedures improve patient aesthetics. A systematic review and Bayesian network meta-analysis. J Clin Periodontol, 2016;43:965-975.

Conflict of Interests: Nothing to declare.

Financial Disclosu re Statement: Nothing to declare.

Human Rights Statement: All the procedures on humans were conducted in accordance with the Helsinki Declaration of 1975, as revised 2000. Consent was obtained from the patient/s and approved for the current study by national ethical committee.

Animal Rights Statement: None required.

Received on May 31, 2020.

Revised on July 28, 2020.

Accepted on September 20, 2020.

Correspondence:

Eleftherios Mitsopoulos

Department of Preventive Dentistry, Periodontology and Implant Biology

Aristotle University of Thessaloniki

Thessaloniki Greece

e-mail: lefterismt95@gmail.com 